\title{
Nasal Administration of Glucosyltransferase-I of Streptococcus sobrinus without Adjuvant Induces Protective Immunity
}

\author{
Keita Watanabe ${ }^{1,2}$, Tomomi Hashizume ${ }^{1,3}$, Tomoko Kurita-Ochiai ${ }^{1,3}$, Yoshiaki Akimoto ${ }^{2,3}$ and Masafumi Yamamoto ${ }^{1,3 *}$ \\ ${ }^{1}$ Department of Microbiology and Immunology, Nihon University School of Dentistry at Matsudo, 2-870-1 Sakaecho-Nishi, Matsudo, Chiba 271-8587, Japan \\ ${ }^{2}$ Department Oral Surgery, Nihon University School of Dentistry at Matsudo, 2-870-1 Sakaecho-Nishi, Matsudo, Chiba 271-8587, Japan \\ ${ }^{3}$ Research Institute of Oral Science, Nihon University School of Dentistry at Matsudo, 2-870-1 Sakaecho-Nishi, Matsudo, Chiba 271-8587, Japan
}

\begin{abstract}
This study seeks to assess the efficacy of the glucosyltransferase-I (GTF-I) produced by Streptococcus sobrinus as a nasal vaccine for the prevention of dental caries. Nasal immunization of mice with GTF-I elicited significant levels of GTF-I-specific IgG and IgA in serum and mucosal IgA antibodies in saliva. Antibody-forming cell analysis confirmed the antibody titers by detecting high numbers of GTF-I-specific antibody-forming cells in spleen and salivary glands. Coadministration of GTF-I and oligodeoxynucleotides (ODN) containing unmethylated cytosine-phosphate-guanine (CpG) dinucleotides (CpG ODN) as adjuvant further elevated salivary IgA antibody responses; however, the increase in serum antibody levels was slight. GTF-I-specific IgG antibodies from mice given GTF-I alone or GTF-I plus CpG ODN inhibited biofilm formation by $S$. sobrinus. Finally, the mice given nasal GTF-I showed protection and significant inhibition of dental caries caused by oral infection with $S$. sobrinus even without the use of CpG ODN. These results suggest that nasal administration of GTF-I could be an important tool for the prevention of dental caries.
\end{abstract}

Keywords: Dental caries; Vaccine; Glucosyltransferase-I; Streptococcus sobrinus

Abbreviations: GTF-I: Glucosyltransferase-I; CpG ODN: Oligodeoxynucleotides containing unmethylated CytosinePhosphate-Guanine Dinucleotides

\section{Introduction}

Dental caries is a chronic infectious disease caused by the formation of biofilm on tooth surfaces. Among the oral bacteria, mutans streptococci are considered to be causative agents of dental caries [1]. Streptococcus sobrinus as well as $S$. mutans are major pathogens of dental caries [2]. Both bacteria produce water-soluble and water-insoluble glucans from sucrose, by the combined action of glucosyltransferases $[1,2]$. The synthesis of the water-insoluble glucan is necessary for the accumulation of these cells on the tooth surface and the induction of dental caries $[3,4]$. S. sobrinus produces a water-insoluble GTF-I. The GTF-I protein consists of two functional domains: an $\mathrm{N}$-terminal sucrose-binding domain and a C-terminal glucan-binding domain [5-7]. The activities of GTF-I are mediated through both catalytic and glucan-binding functions $[8,9]$.

If an effective vaccine for the oral cavity is to be designed, careful consideration must be given to the various immune responses and antigen-delivery systems. Because of the risk of needle-borne diseases associated with reuse and improper disposal of needles, needle-free delivery has become a global priority. Nasal administration of vaccine has been widely used for mucosal immunization because it delivers antigen directly to IgA-inductive sites termed nasal-associated lymphoid tissues without the influence of enzymes and acids in the gastrointestinal tract. Furthermore, this form of immunization is capable of inducing both mucosal and systemic immune responses, which result in two layers of host protection against infectious diseases [10,11].

CpG dinucleotides in microbial DNA sequences activate Tolllike receptor 9, and previous studies have shown that $\mathrm{CpG}$ ODN can reiterate the majority of the immunomodulatory effects produced by bacterial DNA CPG [12-14]. In this regard, several studies have reported that parenteral immunization of animals with various antigens plus $\mathrm{CPG}$ ODN as adjuvant induces $\mathrm{T}$ helper (Th)1-type responses [15-17]. Furthermore, it has been shown that CPG ODN is a potent adjuvant when given nasally $[18,19]$.

The major aim of the present study is to assess the potential of a nasal vaccine containing GTF-I with or without CpG ODN to prevent oral infection by $S$. sobrinus. The results suggest that nasal GTF-I is a practical and effective vaccine candidate for induction of protective immunity against dental caries caused by $S$. sobrinus infection.

\section{Materials and Methods}

\section{Mice}

BALB/c mice were purchased from Sankyo Lab Services (Tokyo, Japan). These mice were maintained under pathogen-free conditions at the experimental facility of the Nihon University School of Dentistry at Matsudo. All mice were randomly assigned into control or experimental groups of 5-6 mice each, and were provided ad libitum access to sterile food and water. They were used at 8-12 weeks of age in accordance with the Guidelines for the Care and Use of Laboratory Animals (Nihon University School of Dentistry at Matsudo).

\section{Antigen and adjuvant}

Recombinant GTF-I was prepared as described previously [20], with

*Corresponding author: Masafumi Yamamoto, Department of Microbiology and Immunology, Nihon University School of Dentistry at Matsudo, 2-870-1 SakaechoNishi, Matsudo, Chiba 271-8587, Japan, Tel: +81-47-360-9336, Fax: +81-47-360 9601, E-mail: yamamoto.masafumi@nihon-u.ac.jp

Received December 08, 2010; Accepted December 30, 2010; Published December 30, 2010

Citation: Watanabe $\mathrm{K}$, Hashizume T, Kurita-Ochiai T, Akimoto $\mathrm{Y}$, Yamamoto M (2010) Nasal Administration of Glucosyltransferase-I of Streptococcus sobrinus without Adjuvant Induces Protective Immunity. J Vaccines Vaccin 1: 109 doi:10.4172/2157-7560.1000109

Copyright: (c) 2010 Watanabe $\mathrm{K}$, et al. This is an open-access article distributed under the terms of the Creative Commons Attribution License, which permits unrestricted use, distribution, and reproduction in any medium, provided the original author and source are credited. 
minor modifications. Briefly, Streptococcus anginosus transformant SS-03E expressing the gtfl were grown in Todd-Hewitt broth (THB, BD Difco, Franklin Lakes, NJ) containing erythromycin anaerobically. Cells were removed by centrifugation and the supernatant was mixed with an equal volume of chilled ethanol. The precipitate was collected by centrifugation, and dissolved in distilled water. Insoluble materials were removed by centrifugation and the supernatant was used as the crude enzyme preparation. This preparation was supplemented with loading buffer, and applied to a preparative PAGE gel column as previously described [21]. Eluted fractions were subjected to mini-slab SDS-PAGE, and the gels were stained with Coomassie brilliant blue or analyzed by Western blotting to confirm. The active fractions were pooled and mixed with chilled ethanol to remove the detergent. The precipitate was collected by centrifugation, and dissolved in distilled water, and dialyzed in PBS. The purity of the protein was determined by SDS-PAGE with silver staining, and no contaminating protein bands were noted. Furthermore, this band displayed GTF activity and synthesized insoluble glucan after incubation with sucrose (Figure 1). Possible residual endotoxin was assessed in the preparation with an LAL pyrochrome kit (Associates of Cape Cod Inc., Woods Hole, MA). The purified GTF-I contained no detectable endotoxin. CpG ODN (5'-TCCATGACGTTCCTGACGTT-3') was purchased from Coley Pharmaceutical Group, Inc. (Wellesley, MA).

\section{Immunization and sample collection}

Mice were immunized nasally on days 0,7 and 14 with a $10 \mu \mathrm{l}$ aliquot ( $5 \mu \mathrm{l}$ per nostril) of PBS containing $20 \mu \mathrm{g}$ of GTF-I alone or $20 \mu \mathrm{g}$ of GTF-I with $10 \mu \mathrm{g}$ of CpG ODN. Serum and saliva samples were collected from each group, as described elsewhere [22], in order to examine GTF-I-specific antibody responses.

\section{Detection of antigen-specific antibody responses}

Antibody titers in serum and saliva were determined by ELISA. Briefly, plates were coated with GTF-I $(5 \mu \mathrm{g} / \mathrm{ml})$ and blocked with PBS containing $1 \%$ bovine serum albumin. After blocking, serial dilutions of serum or saliva samples were added in duplicate. The starting dilution of serum was $1: 2^{7}$, while that of saliva was $1: 2^{2}$. The plates were incubated for $4 \mathrm{~h}$ at room temperature, washed and then incubated with goat horseradish peroxidase-conjugated anti-mouse $\gamma$ or $\alpha$ heavy chain-specific antibodies (Southern Biotechnology Associates, Birmingham, $\mathrm{AL}$ ) at $4^{\circ} \mathrm{C}$ for $20 \mathrm{~h}$. Finally, 2,2'-azino-bis (3-ethylbenzo-thiazoline-6-sulfonic acid) with $\mathrm{H}_{2} \mathrm{O}_{2}$ (Moss, Inc., Pasadena, MD) was added for color development. Endpoint titers were expressed as the reciprocal $\log _{2}$ of the last dilution that gave an optical density at $415 \mathrm{~nm}$ of 0.1 greater than non-immunized control samples after 15 min of incubation.

\section{Assessment of antibody-forming cells}

Single cell suspensions were obtained from the spleen and salivary glands, as described previously [23]. Briefly, salivary glands were carefully excised, teased apart, and dissociated using $0.3 \mathrm{mg} /$ $\mathrm{ml}$ collagenase (Nitta Gelatine Co. Ltd., Osaka, Japan) in RPMI 1640 (Wako Pure Chemical Industries Ltd., Osaka, Japan). Mononuclear cells from salivary glands were obtained at the interface of the $50 \%$ and 75\% layers of a discontinuous Percoll gradient (GE Healthcare UK, Ltd., Amersham Place, Little Chalfont, England). To assess numbers of antigen-specific antibody-forming cells, an ELISPOT assay was performed as previously described [22]. Briefly, 96-well nitrocellulose plates (BD Biosciences, Franklin Lakes, NJ) were coated with GTF-I $(5 \mu \mathrm{g} / \mathrm{ml})$, incubated for $20 \mathrm{~h}$ at $4^{\circ} \mathrm{C}$ and were then washed extensively and blocked with RPMI 1640 containing 10\% fetal calf serum. After 30 min, blocking solution was discarded, and lymphoid cell suspensions at various dilutions were added to wells and incubated for $4 \mathrm{~h}$ at $37^{\circ} \mathrm{C}$ in $5 \% \mathrm{CO}_{2}$ in moist air. Detection antibodies included goat horseradish peroxidase-conjugated anti-mouse $\gamma$ or $\alpha$ heavy chainspecific antibodies (Southern Biotechnology Associates). Following overnight incubation, plates were washed with PBS and developed by addition of 3-amino-9-ethylcarbazole dissolved in $0.1 \mathrm{M}$ sodium acetate buffer containing $\mathrm{H}_{2} \mathrm{O}_{2}$ (Moss) to each well. Plates were incubated at room temperature for $25 \mathrm{~min}$ and were washed with water, and antibody-forming cells were then counted with the aid of a stereomicroscope (Olympus, Tokyo, Japan).

\section{Biofilm assay}

Serum $\operatorname{Ig} G$ antibodies from immunized mice were purified using a HiTrap ${ }^{\mathrm{TM}}$ protein G HP column (Amersham Biosciences, Piscataway, $\mathrm{MJ}$ ). Biofilm formation by $S$. sobrinus was quantitatively measured using a modified version of the microplate adherence assay as described previously [24]. Briefly, S. sobrinus cells (approximately 2.5 $\mathrm{x} 10^{6} \mathrm{cells} / \mathrm{ml}$ ) were pre-incubated with purified $\operatorname{IgG}$ antibodies at $37^{\circ} \mathrm{C}$ for 1 h. S. sobrinus suspension $(200 \mu \mathrm{l})$ in brain-heart infusion broth (Difco, Detroit, MI), supplemented with $1 \%$ sucrose was then placed in a 96-well flat-bottomed tissue culture plate (Life Technologies, Paisley, UK). After static incubation for $24 \mathrm{~h}$ at $37^{\circ} \mathrm{C}$ in anaerobic conditions, wells were emptied, washed three times with PBS and air-dried, and adherent growth was stained with $0.1 \%$ safranin (Sigma, St. Louis, MO) for $30 \mathrm{~min}$. The wells were rinsed with distilled water and adherent material was solubilised through incubation with $200 \mu \mathrm{l}$ of $0.2 \mathrm{M}$ sodium hydroxide for $1 \mathrm{~h}$ at $80^{\circ} \mathrm{C}$. The absorbance for each strain was measured at $540 \mathrm{~nm}$.

\section{Oral infection and caries assessment}

Mice were orally infected with $S$. sobrinus as described previously [25], with minor modifications. In brief, 2 weeks after the last immunization, the mice were given cariogenic diet, diet 2000 containing ampisilin, chloramphenicol, and carbenisillin (1 $\mathrm{mg} / \mathrm{g}$ of food). The mice were then infected orally with $10^{9} \mathrm{CFU}$ of streptomycin-resistant $S$. sobrinus 6715 on 4 consecutive days. Sixty days after the first gavage, mice were euthanized using $\mathrm{CO}_{2}$ and the mandibles were removed and then scanned using micro-computed tomography (Rigaku-mCT ${ }^{\circledR}$, Tokyo, Japan) to assess the caries activity. For scanning, the X-ray source was operated at $75 \mathrm{kV}$ and $50 \mu \mathrm{A}$. Each mandible was set on the object stage and imaging was performed on the sample over a full $360^{\circ}$ rotation with an exposure time of $2 \mathrm{~min}$. An isotropic resolution of $100 \times 100 \times 100 \mu \mathrm{m}$ voxel size was selected.

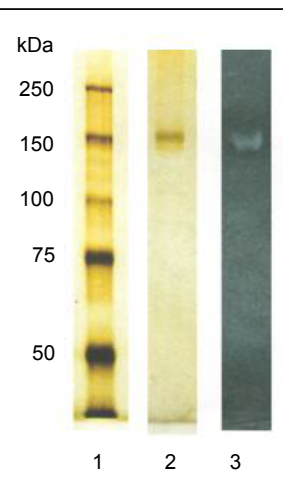

Figure 1: SDS-PAGE analysis of purified GTF-I. The purified GTF-I was subjected to SDS PAGE. After electrophoresis, the gel was stained with silver (lane 2), or incubated with sucrose to detect insoluble glucan synthesis (lane 3). Lane 1 shows a protein standard. 

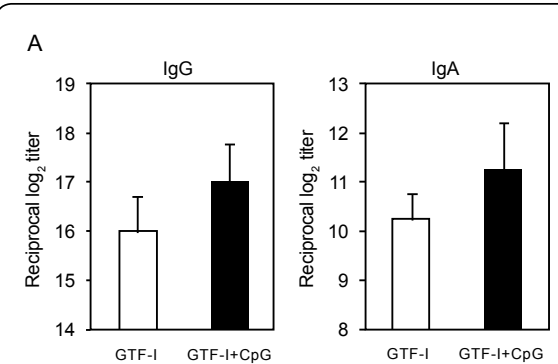

B

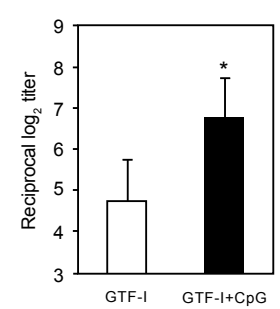

Figure 2: GTF-I-specific serum $\lg G$ and $\lg A(A)$, and $\lg A$ antibody titers in saliva (B). Groups of mice were nasally immunized with $20 \mu \mathrm{g}$ of GTF-I alone (open bars) or $20 \mu \mathrm{g}$ of GTF-I plus $10 \mu \mathrm{g}$ of CpG ODN (closed bars) on days 0,7 , and 14 . Serum and saliva samples were collected at day 21 and were assessed for 40k-OMP-specific antibody titers. The results are expressed as the mean $\pm S$.E. obtained for five mice per group. The $P$ values for serum IgG, IgA and salivary IgA antibody titers with GTF-I alone or with GTF-I plus CpG ODN are $<0.05$ when compared with PBS. ${ }^{*} p<0.05$, compared with GTF-I alone.
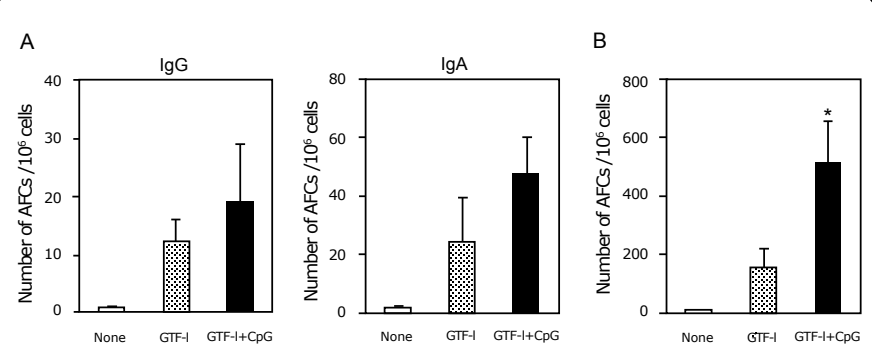

Figure 3: GTF-I-specific IgG and IgA antibody-forming cells (AFCs) in spleen (A), and IgA AFCs in salivary glands (B). Groups of mice were nasally immunized with PBS (open bars), GTF-I alone (dotted bars), or GTF-I plus CpG ODN (closed bars) as described in the legend of Figure 1. Mononuclear cells were isolated at day 21 and, AFC responses were examined. The results are expressed as the mean \pm S.E. obtained for five mice per group. The $P$ values for IgG and IgA AFCs in spleen as well as IgA AFCs in salivary glands with GTF-I alone or with GTF-I plus CpG ODN are $<0.05$ when compared with PBS. * $p<0.05$, compared with GTF-I alone.

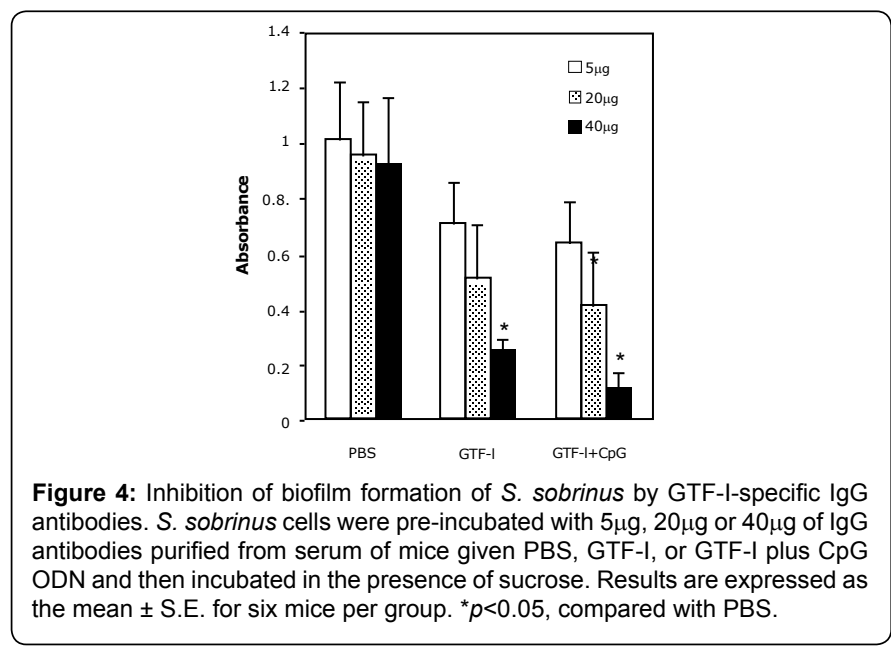

The original 3D images were displayed and analyzed with I-View ${ }^{\circledR}$ software (J. Morita, Kyoto, Japan). The caries activity was determined as previously described [26].

\section{Statistical analysis}

Results were expressed as means \pm standard error (S.E.). Statistical significance $(p<0.05)$ was determined by Mann-Whitney $\mathrm{U}$ test for unpaired samples.

\section{Results}

Induction of GTF-I-specific antibody responses by nasal immunization with GTF-I

To evaluate the ability of nasally administered GTF-I to induce antibody responses, a group of mice was nasally immunized with GTF-I alone. When the antigen-specific immune responses were analyzed by ELISA, serum IgG and IgA anti-GTF-I antibody responses were detected (Figure 2A). In addition, nasal administration of GTF-I alone induced significant levels of GTF-I-specific IgA antibody responses in saliva (Figure 2B). The results of serum antibody titers were confirmed by antibody-forming cell responses which indicated significant numbers of GTF-I-specific IgG- and IgA-forming cells in spleen of mice given GTF-I alone (Figure 3A). In the next study, to determine whether IgA antibody responses in external secretions were mucosa-associated or, alternatively, were exudates from serum, the numbers of GTF-I-specific IgA-forming cells in salivary glands were counted. As shown in Figure 3B, high numbers of IgA-forming cells were found in the salivary glands of mice given GTF-I alone.

Since mucosal (e.g., nasal or oral) administration of CPG ODN with protein antigen have proven to be an effective regimen for the induction of antigen-specific antibody responses $[18,19]$, we next examined the effect of the nasal administration of CpG ODN as adjuvant on GTF-I-specific antibody responses. Mice nasally immunized with GTF-I plus CpG ODN showed significantly higher salivary IgA anti-GTF-I antibody responses than did those immunized with GTF-I alone; however, the increase in serum $\operatorname{IgG}$ and $\operatorname{IgA}$ titers was slight (Figures 2A and 2B). Antibody-forming cell responses showed significantly higher numbers of antibody-forming cells in salivary glands, but not spleen, of mice immunized with GTF-I plus CPG ODN than those of mice given GTF-I alone (Figures 3A and 3B).

\section{Nasally GTF-I-induced antibodies suppress biofilm formation by $S$. sobrinus}

In the next study, we sought to determine whether antibodies induced by nasally administered GTF-I was capable of suppressing biofilm formation by $S$. sobrinus. To this end, $S$. sobrinus were pre-treated with IgG from mice given GTF-I alone, GTF-I plus CpG or PBS as control and then incubated with $1 \%$ sucrose. The results showed that biofilm formation of $S$. sobrinus was inhibited by $\operatorname{IgG}$ antibodies from mice given GTF-I alone or GTF-I plus CPG ODN in a dose-dependent manner (Figure 4).

\section{Nasal GTF-I reduces the development of dental caries caused by oral infection with $S$. sobrinus}

As nasal GTF-I elicited significant GTF-I-specific antibody responses in serum and saliva; we sought to determine whether these antibodies were capable of suppressing dental caries caused by oral infection with $S$. sobrinus. Thus, mice given GTF-I alone or GTF-I plus $\mathrm{CpG}$ ODN were infected orally with $S$. sobrinus 2 weeks after the last immunization. Mice immunized with GTF-I alone demonstrated significant fewer enamel (E) and dentinal slight (Ds) lesions than did those given PBS. Furthermore, dentinal moderate (Dm) and dentinal extensive (Dx) lesions were not found in these immunized mice. Mice immunized with GTF-I plus CPG ODN had no Ds, Dm and Dx lesions, while there was no obvious difference in $\mathrm{E}$ lesions between mice given GTF-I alone and mice given GTF-I plus CpG ODN (Figure 5). These findings indicate that nasal immunization with GTF-I alone provides protection against oral infection by $S$. sobrinus. 


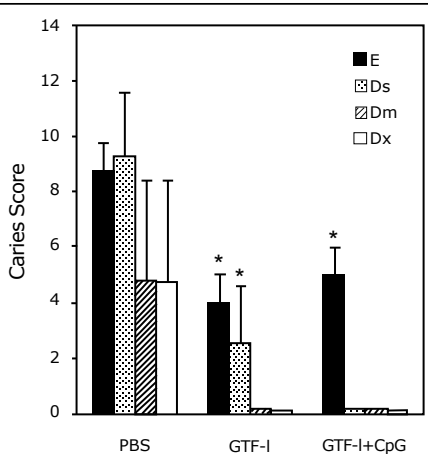

Figure 5: Reduction of $S$. sobrinus-induced dental caries by nasal GTF-I vaccine. Groups of mice were immunized nasally with GTF-I alone, GTF-I plus CpG ODN or PBS, as described in the legend for Figure 1. Two weeks after immunization, mice given PBS, GTF-I alone or GTF-I plus CpG ODN were inoculated orally with $10^{9} \mathrm{CFU}$ of $\mathrm{S}$. sobrinus, as described in Materials and Methods. Caries activities were determined by Keyes method. Results are expressed as the mean \pm S.E. for six mice per group. ${ }^{*} p<0.05$, compared with PBS.

\section{Discussion}

S. sobrinus as well as $S$. mutans produce water-insoluble glucans that provide scaffolding for the aggregation of mutans and other oral streptococci $[1,2]$. Thus, the important role of GTF-I in the cariogenicity of mutans streptococci makes them rational targets for the development of an anticaries vaccine. A previous study has shown that specific antibodies induced by a fusion protein consisting of alanine-rich region of surface protein antigen $(\mathrm{PAg})$ and GTF-I produced by $S$. sobrinus suppress sucrose-dependent and -independent adhesion of both $S$. sobrinus and $S$. mutans [27]. Furthermore, immunization with the plasmid encoding the surface protein (PAc) of $S$. mutans and GTF glucan-binding domain of $S$. sobrinus GTF-I or the catalytic regions of $S$. sobrinus GTF-I induced protective antibody responses against the oral infection with $S$. mutans and $S$. sobrinus $[28,29]$. The development of a nasal GTF-I vaccine for human use may be a significant milestone in the quest for an effective anticaries vaccine. In assessing the efficacy of nasally administered GTF-I, we found that GTF-I alone induced significant antigen-specific antibody responses in both serum and saliva samples, while GTF-I plus CPG ODN as adjuvant further increased the levels of salivary antibody responses. The GTF-I-specific $\operatorname{IgG}$ antibodies induced by the nasal vaccine significantly diminished biofilm formation by $S$. sobrinus. Furthermore, mice given GTF-I alone or GTF-I plus CPG ODN were significantly protected against the development of dental caries caused by oral infection with $S$. sobrinus. These results suggest that nasal immunization with GTF-I may be an effective antigen delivery system for the induction of protective immune responses against $S$. sobrinus as well as $S$. mutans infection.

It is important to note that nasal immunization with GTF-I alone elicited significant serum $\operatorname{Ig} G, \lg A$ as well as salivary $\operatorname{Ig} A$ antibody responses. Protein antigen given via the mucosal route without adjuvant has been generally reported to be only a weak immunogen and so has been presumed to require a mucosal adjuvant to induce antigen-specific antibody responses [11]. Indeed, nasal administration of CPG ODN as adjuvant induced significantly higher levels of GTF-Ispecific salivary IgA antibody responses than did nasal administration of GTF-I alone, clearly indicating that CPG ODN is an effective adjuvant for nasal immunization. Though these studies suggest that CpG ODN is an effective adjuvant for nasal GTF-I, it would be more prudent not to use to avoid unnecessary side effects induced by
CpG ODN. Even without CPG ODN, specific IgG antibodies induced by the nasal GTF-I significantly diminished biofilm formation by $S$. sobrinus. Furthermore, these immunized mice displayed significantly fewer E, Dm, and Dx lesions than did non-immunized mice. These interesting outcomes could be explained by the immunogenicity of GTF-I. It may be that GTF-I, as a key virulence factor for synthesis of water-insoluble glucan by $S$. sobrinus [5-9], possesses especially strong immunogenicity, eliminating the need for an adjuvant. Indeed, an earlier study has demonstrated that oral immunization of hamster with GTF complex of $S$. mutans without adjuvant induces serum and salivary antibody responses [30]. Furthermore, nasal immunization with the glucan-binding domain of $S$. mutans GTF-I elicits protective antibody responses against $S$. mutans infection even in the absence of adjuvant [31].

Alternatively, the route of immunization may particularly effective. In this study, we chose intranasal administration as the delivery route because it delivers antigen directly with IgA-inductive sites termed nasal-associated lymphoreticular tissues without the influence of enzymes and acids in the gastrointestinal tract. It may be that the combination of nasal immunization and GTF-I is a particularly effective vaccine regimen for the induction of antigen-specific antibody responses in saliva and serum. Such a regimen, which might not require adjuvant for induction of protective immune responses, would make for a most attractive candidate for a human vaccine. Since GTF-I catalyzes the hydrolysis of the glucosidic linkage of sucrose, resulting in the release of glucose and fructose and the transfer of the glucosyl moiety to a terminal site on the growing glucan molecules which contribute to the development of dental plaque [32], it is not toxic for humans. Indeed, previous studies have shown that human volunteers immunized with $S$. mutans GTFs possess no side effects during or after immunization [33,34]. Taken together, these findings suggest that the nasal administration of GTF-I can be considered to be a practical and effective route of immunization for the induction of specific immunity against $S$. sobrinus infection.

It is well established that the mucosal immune system exists alongside and separate from the systemic immune system [35]. Therefore, the induction of systemic immune responses by parenteral immunization does not result in significant mucosal immunity. However, mucosal immunization can and often does result in protective immunity not only in external secretions but in systemic compartments as well [35]. In many ways, the oral cavity is an important and characteristic compartment of the mucosal immune system. However, it differs from other mucosal compartments because its local immune responses are both mucosal and systemic. Local immune responses emanating from the salivary gland are part of the mucosal immune system while those emanating from the crevicular fluid derived from tissue fluids in blood capillaries are part of the systemic immune system [36]. Thus, although the main isotype of the oral cavity is secretory $\operatorname{Ig} \mathrm{A}$, it is clear that systemic-derived $\operatorname{lgG}$ in crevicular fluid is also biologically active within the oral cavity. Thus, effective protection against $S$. sobrinus infection requires both mucosal and systemic antibody responses.

In summary, our current study provides evidence that nasal administration of GTF-I elicits GTF-I-specific serum $\operatorname{IgG}$, IgA and salivary IgA antibody responses. Importantly, these antibody responses were induced without the use of $\mathrm{CPG}$ ODN as adjuvant. GTF-I-specific immune responses induced by nasal GTF-I provided protective immunity against dental caries caused by $S$. sobrinus infection. These findings suggest that nasal immunization with GTF-I effectively elicit protective levels of antibodies to $S$. sobrinus and 
Citation: Watanabe K, Hashizume T, Kurita-Ochiai T, Akimoto Y, Yamamoto M (2010) Nasal Administration of Glucosyltransferase-I of Streptococcus sobrinus without Adjuvant Induces Protective Immunity. J Vaccines Vaccin 1: 109. doi:10.4172/2157-7560.1000109

Page 5 of 5

therefore may act as an effective and safe vaccine delivery system for prevention of dental caries.

\section{Acknowledgments}

We thank Dr. Mitsuo Hayakawa for technical support in purification of GTFand Dr. Noboru Kuboyama for technical support in micro-computed tomography examination. This work was supported by grants-in-aid for scientific research (22592102, 22390398 and 22791816) from the Japan Society for the Promotion of Science and an "Academic Frontier" Project for Private Universities matching fund subsidy from the Ministry of Education, Culture, Sports, Science and Technology, 2007-2011.

\section{References}

1. Hamada S, Slade HD (1980) Biology, immunology, and cariogenicity of Streptococcus mutans. Microbiol Rev 44: 331-384.

2. Loesche WJ (1986) Role of Streptococcus mutans in human dental decay. Microbiol Rev 50: 353-380.

3. Yamashita Y, Bowen WH, Burne RA, Kuramitsu HK (1993) Role of the Streptococcus mutans gtf genes in caries induction in the specific-pathogenfree rat model. Infect Immun 61: 3811-3817.

4. Koga T, Asakawa H, Okahashi N, Hamada S (1986) Sucrose-dependent cel adherence and cariogenicity of serotype c Streptococcus mutans. J Gen Microbiol 132: 2873-2883.

5. Kuramitsu HK, Smorawinska M, Nakano YJ, Shimamura A, Lis M (1995) Analysis of glucan synthesis by Streptococcus mutans. Dev Biol Stand 85: 303-307.

6. Abo H, Matsumura T, Kodama T, Ohta H, Fukui K, et al. (1991) Peptide sequences for sucrose splitting and glucan binding within Streptococcus sobrinus glucosyltransferase (water-insoluble glucan synthetase). J Bacteriol 173: 989-996.

7. Ferretti JJ, Gilpin ML, Russell RR (1987) Nucleotide sequence of a glucosyltransferase gene from Streptococcus sobrinus MFe28. J Bacteriol 169: 4271-4278.

8. Smith DJ (2002) Dental caries vaccines: prospects and concerns. Crit Rev Oral Biol Med 13: 335-349.

9. Koga T, Oho T, Shimazaki Y, Nakano Y (2002) Immunization against dental caries. Vaccine 20: 2027-2044.

10. Holmgren J, Czerkinsky C (2005) Mucosal immunity and vaccines. Nat Med 11: S45-53.

11. Holmgren J, Czerkinsky C, Eriksson K, Mharandi A(2003) Mucosal immunisation and adjuvants: a brief overview of recent advances and challenges. Vaccine 21 Suppl 2: S89-95

12. Yi AK, Klinman DM, Martin TL, Matson S, Krieg AM (1996) Rapid immune activation by $\mathrm{CpG}$ motifs in bacterial DNA. Systemic induction of IL-6 transcription through an antioxidant-sensitive pathway. J Immunol 157: 53945402.

13. Klinman DM, Yi AK, Beaucage SL, Conover J, Krieg AM (1996) CpG motifs present in bacteria DNA rapidly induce lymphocytes to secrete interleukin 6 , interleukin 12, and interferon gamma. Proc Natl Acad Sci USA 93: 2879-2883.

14. Krieg AM, Yi AK, Matson S, Waldschmidt TJ, Bishop GA, et al. (1995) CpG motifs in bacterial DNA trigger direct B-cell activation. Nature 374: 546-549.

15. Chu RS, Targoni OS, Krieg AM, Lehmann PV, Harding CV (1997) CpG oligodeoxynucleotides act as adjuvants that switch on $\mathrm{T}$ helper 1 (Th1) immunity. J Exp Med 186: 1623-1631.

16. Davis HL, Weeratna R, Waldschmidt TJ, Tygrett L, Schorr J, et al. (1998) CpG DNA is a potent enhancer of specific immunity in mice immunized with recombinant hepatitis B surface antigen. J Immunol 160: 870-876.

17. Roman M, Martin-Orozco E, Goodman JS, Nguyen MD, Sato Y, et al. (1997) Immunostimulatory DNA sequences function as $T$ helper-1-promoting adjuvants. Nat Med 3: 849-854.
18. McCluskie MJ, Davis HL (1998) CpG DNA is a potent enhancer of systemic and mucosal immune responses against hepatitis B surface antigen with intranasal administration to mice. J Immunol 161: 4463-4466.

19. Moldoveanu Z, Love-Homan L, Huang WQ, Krieg AM (1998) CpG DNA, a nove immune enhancer for systemic and mucosal immunization with influenza virus. Vaccine 16: 1216-1224.

20. Shinozaki-Kuwahara N, Shiroza T, Hayakawa M, Abiko Y, Fukushima K (2005) Expression of the gtfl gene from Streptococcus sobrinus in Streptococcus anginosus using integration-mediated transformation system. Biochim Biophys Acta 1722: 189-199.

21. Hayakawa M, Hosogi Y, Takiguchi H, Shiroza T, Shibata Y, et al. (2003) Further development of an electroosmotic medium pump system for preparative disk gel electrophoresis. Anal Biochem 313: 60-67.

22. Yamamoto M, Briles DE, Yamamoto S, Ohmura M, Kiyono $H$, et al. (1998) A nontoxic adjuvant for mucosal immunity to pneumococcal surface protein $A$. $J$ Immunol 161: 4115-4121.

23. Mega J, McGhee JR, Kiyono H (1992) Cytokine- and Ig-producing T cells in mucosal effector tissues: analysis of IL-5- and IFN-gamma-producing T cells, $\mathrm{T}$ cell receptor expression, and IgA plasma cells from mouse salivary glandassociated tissues. J Immunol 148: 2030-2039.

24. Blake JE, Metcalfe MA (2001) A Shared noncapsular antigen is responsible for false-positive reactions by Staphylococcus epidermidis in commercia agglutination tests for Staphylococcus aureus. J Clin Microbiol 39: 544-550.

25. Michalek SM, McGhee JR (1977) Virulence of Streptococcus mutans: an antibiotic-suppressed rat model for studies of pathogenesis. J Dent Res 56 205-211.

26. Keyes PH (1958) Dental caries in the molar teeth of rats. II. A method for diagnosing and scoring several types of lesions simultaneously. J Dent Res 37: 1088-1099.

27. Kawato T, Yamashita Y, Katono T, Kimura A, Maeno M (2008) Effects of antibodies against a fusion protein consisting of parts of cell surface protein antigen and glucosyltransferase of Streptococcus sobrinus on cell adhesion of mutans streptococci. Oral Microbiol Immunol 23: 14-20.

28. Sun J, Yang X, Xu QA, Bian Z, Chen Z, et al. (2009) Protective efficacy of two new anti-caries DNA vaccines. Vaccine 27: 7459-7466.

29. Niu Y, Sun J, Fan M, Xu QA, Guo J, et al. (2009) Construction of a new fusion anti-caries DNA vaccine. J Dent Res 88: 455-460.

30. Smith DJ, Taubman MA, Ebersole JL (1980) Local and systemic antibody response to oral administration of glucosyltransferase antigen complex. Infect Immun 28: 441-450.

31. Jespersgaard C, Hajishengallis G, Huang $Y$, Russell MW, Smith DJ, et al (1999) Protective immunity against Streptococcus mutans infection in mice after intranasal immunization with the glucan-binding region of $\mathrm{S}$. mutans glucosyltransferase. Infect Immun 67: 6543-6549.

32. Mooser G, Hefta SA, Paxton RJ, Shively JE, Lee TD (1991) Isolation and sequence of an active-site peptide containing a catalytic aspartic acid from two Streptococcus sobrinus alpha-glucosyltransferases. J Biol Chem 266: 89168922.

33. Childers NK, Tong G, Li F, Dasanayake AP, Kirk K, et al. (2002) Humans immunized with Streptococcus mutans antigens by mucosal routes. J Dent Res 81: $48-52$.

34. Childers NK, Tong G, Mitchell S, Kirk K, Russell MW, et al. (1999) A controlled clinical study of the effect of nasal immunization with a Streptococcus mutans antigen alone or incorporated into liposomes on induction of immune responses. Infect Immun 67: 618-623.

35. Kunisawa J, Nochi T, Kiyono H (2008) Immunological commonalities and distinctions between airway and digestive immunity. Trends Immunol 29: 505513

36. Challacombe SJ, Shirlaw PJ (1999) Immunity of diseases of the oral cavity: Mucosal Immunology. Academic Press, San Diego, CA. 